\title{
Predictive Role of External Carotid Artery Vasospasm on Cerebral Ischemia After Subarachnoid Hemorrhage: Experimental Study
}

\author{
Nuriye Guzin OZDEMIR ${ }^{1}$, Mehmet Dumlu AYDIN² ${ }^{2}$, coskun YOLAS ${ }^{3}$, Ayhan KANAT ${ }^{4}$, Akin LEVENT ${ }^{5}$, \\ Cemal GUNDOGDU ${ }^{6}$, Nazan AYDIN ${ }^{7}$
}

${ }^{1}$ Istanbul Training and Research Hospital, Neurosurgery Clinic, Istanbul, Turkey

${ }^{2}$ Ataturk University, Faculty of Medicine, Department of Neurosurgery, Erzurum, Turkey

${ }^{3}$ Erzurum Regional Training and Research Hospital, Neurosurgery Clinic, Erzurum, Turkey

${ }^{4}$ Recep Tayyip Erdogan University, Faculty of Medicine, Department of Neurosurgery, Rize, Turkey

${ }^{5}$ Ataturk University, Faculty of Medicine, Department of Radiology, Erzurum, Turkey

${ }^{6}$ Ataturk University, Faculty of Medicine, Department of Pathology, Erzurum, Turkey

${ }^{7}$ Bakırkoy Research and Training Hospital, Psychiatry Clinic, Istanbul, Turkey

\section{ABSTRACT}

AIM: Cerebral vasospasm after subarachnoid hemorrhage (SAH) may lead to a devastating neurological outcome by inducing cerebral ischemia. However the role of external carotid artery (ECA) vasospasm has been rarely reported in the literature. The aim of this study was to elucidate the effect of ECA vasospasm on cerebral ischemia related neurodegeneration in the cerebral cortex after SAH.

MATERIAL and METHODS: This study was performed on 23 rabbits, divided into three groups: control ( $n=5)$, sham ( $n=5)$, and SAH $(\mathrm{n}=13)$. Experimental SAH was performed by injecting $0.75 \mathrm{~mL}$ auricular arterial homologous blood into the cisterna magna. After three weeks, the animals were decapitated and the common carotid arteries with their external and internal branches and the brains were examined histopathologically. Vasospasm indexes (VSI) of ECAs and internal carotid arteries (ICAs) and degenerated glial cell numbers of temporal cortices $\left(\mathrm{n} / \mathrm{mm}^{3}\right)$ were estimated stereologically and the results were compared statistically.

RESULTS: Temporal cortex glial cell density was estimated as $136.950 \pm 9.257 / \mathrm{mm}^{3}$ in normal rabbits, $131.324 \pm 7.987 / \mathrm{mm}^{3}$ in sham, $112.320 \pm 6.112 / \mathrm{mm}^{3}$ in light, and $97.543 \pm 5.432 / \mathrm{mm}^{3}$ in severe ECA vasospasm. The mean VSI values of ECA of all groups were $1.95 \pm 0.21,2.15 \pm 0.29,2.95 \pm 0.65$ and $3.12 \pm 0.276$, respectively. Statistical differences between the VSI values of ECA and degenerated neuron densities in temporal cortices were significant $(p<0.005)$.

CONCLUSION: ECA vasospasm was observed to have a more important predictive role on the serious cerebral ischemia and neuronal degeneration after SAH. The mechanism may be related to ischemia of the parasympathetic ganglia of the lower cranial nerves and dorsal root ganglion.

KEYWORDS: Cerebral ischemia, Cerebral vasospasm, External carotid artery vasospasm, Subarachnoid hemorrhage 


\section{INTRODUCTION}

0 ubarachnoid hemorrhage (SAH) accounts for $5-10 \%$ of all cerebrovascular accidents. Cerebral vasospasm is the vasoconstriction of the arteries of the circle of Willis leading to secondary cerebral ischemia. Symptomatic vasospasm occurs 4-12 days after SAH with a peak incidence between 6 and 10 days. The predictors of cerebral vasospasm are the volume, density and prolonged presence of subarachnoid blood. The impairment of cerebral autoregulation and decreased blood flow results in delayed ischemic injury. Angiographic vasospasm is identified in $70 \%$ of the patients while $40 \%$ have clinical vasospasm, and delayed ischemic injury is seen in $30 \%$ of the patients $(21,48)$.

The pathogenesis of the cerebral vasospasm is still not fully understood. Vasoconstriction of the pial vessels with smooth muscle and myofibroflast proliferation with cellular necrosis and remodeling, intimal hyperplasia, collagen deposition and fibrosis as well as intraluminal platelet aggregation with microthrombus formation, arterial thrombosis and distal embolization have been described (21). Impairment of the nitric oxide pathway and neuronal nitric oxide synthase containing neurons in the adventitia is one of the mechanisms (29). Research has shown the inflammatory role of the cytokines, cell adhesion molecules, and leukocytes on the development of cerebral vasospasm (16).

$\mathrm{SAH}$ causes cerebral vasospasm through various neurohumoral mechanisms. Cerebral arteries are innervated by several systems contributing to the autonomic control of cerebral blood flow. Parasympathetic fibers have vasodilatory effects, and sympathetic fibers are vasospastic on cerebral arteries. The neuron density of peripheral nerve ganglions plays a regulatory role in these functions $(9,25)$.

Cerebrovascular sensory nerves are mainly from the trigeminocerebrovascular system. The trigeminal sensory nerves project to the ipsilateral internal carotid artery (ICA), middle cerebral artery (MCA), anterior cerebral artery (ACA), the rostral part of the basilar artery, the posterior cerebral artery (PCA), and the posterior communicating artery $(11,35)$.

Cerebral ischemia and infarction lead to poor outcome and death. The use of nimodipine, hemodynamic treatment, endovascular procedures, and the recent use of endothelin antagonist for prevention of vasospasm have improved the prospects for these patients but outcomes remain poor (47).

External carotid artery (ECA) vasospasm has not been much defined in the literature. In case of cerebral vasospasm, the collateral system helps to save the brain and initiates its selftreating process. However, external carotid spasm together with cerebral vasospasm impairs this collateral salvation network and leads to neurodegeneration of the temporal area supplied by both the internal and external carotid system.

This study investigates the pathogenesis of the cerebral vasospasm with an emphasis on ECA vasospasm and the relationship with decreased parasympathetic activity in order to help develop new therapeutic methods.

\section{MATERIAL and METHODS}

This study has been conducted on 23 rabbits. The animals were divided into 3 groups: $\mathrm{SAH}(n=13)$, sham $(n=5)$ and control $(n=5)$ group. The animal protocols were approved by the Ethics Committee of Erzurum Ataturk University Medical Faculty. The care of the animals and the experiments themselves were conducted according to the guidelines set forth by the same ethics committee. A balanced, injectable anesthetic was used in order reduce pain and mortality. After anesthesia was induced with isoflurane given by a facemask, $0.2 \mathrm{~mL} / \mathrm{kg}$ of the anesthetic combination (Ketamine HCL, $150 \mathrm{mg} / 1.5 \mathrm{~mL}$; Xylazine HCL, $30 \mathrm{mg} / 1.5 \mathrm{~mL}$; and distilled water, $1 \mathrm{~mL}$ ) was subcutaneously injected before surgery. During the procedure, a dose of $0.1 \mathrm{~mL} / \mathrm{kg}$ of the anesthetic combination was used when required. Autologous blood $(0.75 \mathrm{~mL})$ was taken from the auricular artery and injected using a 22-gauge needle into the cisterna magna of animals in the $\mathrm{SAH}$ group over the course of 1 minute. In the sham group, $1 \mathrm{~mL}$ of physiological saline was injected into the cisterna magna. Electrocardiography and respiratory rhythm parameters were monitored once/day and animals were decapitated after 3 weeks. Their common carotid arteries and brains were extracted bilaterally and fixed with $10 \%$ formalin solution for four days. Sections of paraffin embedded brains at the levels of superior temporal gyri and common carotid arteries at the just post-bifurcation levels were taken and stained with hematoxylin \& eosin (H\&E) and terminal deoxynucleotidyl transferase dUTP nick end labeling (TUNEL) for SAH-related apoptotic damage detection and examined stereologically. In order to detect hypertrophy, vasospasm, endothelial apoptosis in the ECA and ICA, vasospasm index (VSI) was used. Vasospasm was observed by the development of smooth muscle cells hypertrophy, arterial wall enlargement, and luminal narrowing. The hypertrophied muscle cells and intimal edema cause thickening of the vessel wall surface. The proportion of ICA or ECA wall section surface values (wall ring) to lumen surface values was accepted as VSI. This index was calculated with the following formula: VSI $=\left(\pi R^{2}-\pi r^{2}\right) /$ $\pi r^{2}=\left(R^{2}-r^{2}\right) / r^{2}$. Low luminal surface values and high VSI index was accepted as prominent vasospasm.

The differences of VSI values of ECA and the temporal cortex cell number data were analyzed using a commercially available statistics software package (SPSS ${ }^{\circledR}$ for Windows v. 12.0, Chicago, USA). The Kruskal-Wallis and Mann-Whitney $U$ tests were used for data analysis. Differences were considered to be significant at $p<0.05$.

\section{RESULTS}

One animal in the sham group and two animals in the SAH group died in the first postoperative week and the remaining animals were followed for 21 days. Fever, meningeal irritation, consciousness, convulsions, apnea, cardiac arrhythmia, and breathing disturbances were observed frequently in the five of the surviving animals of the study group. Angiographic appearance of normal caroticovertebral arteries and histopathological appearance of a normal ECA-ICA (Figure 1) and of the ECA-ICA after SAH-without vasospasm were seen (Figure 2). There were no inflammatory changes in the arteries but intimal 
derangement was observed in a rabbit with slight ECA vasospasm (Figure 3). Minimally convoluted inner elastic membrane, swelling endothelial and contracted smooth muscle cells, and thickened vessel walls were seen. Among animals with severe vasospasm, we observed intimal hypertrophy and prominent luminal narrowing in the ECA and ICA of a rabbit with severe temporal lobe neurodegeneration (Figure 4). A convoluted inner elastic membrane (IEM) and swelling of the endothelial and contracted smooth muscle cells (SMC), endothelial cell loss, luminal narrowing, endothelial basal lamina rupture, and thickened vessel wall were seen. Prominent vascular hypertrophy, endothelial and muscular and also adventitial proliferation were observed. The stereological neuron estimation method is summarized in Figure 5, and the VSI calculation method is shown in Figure 6 A, B. Figure 7 shows his-

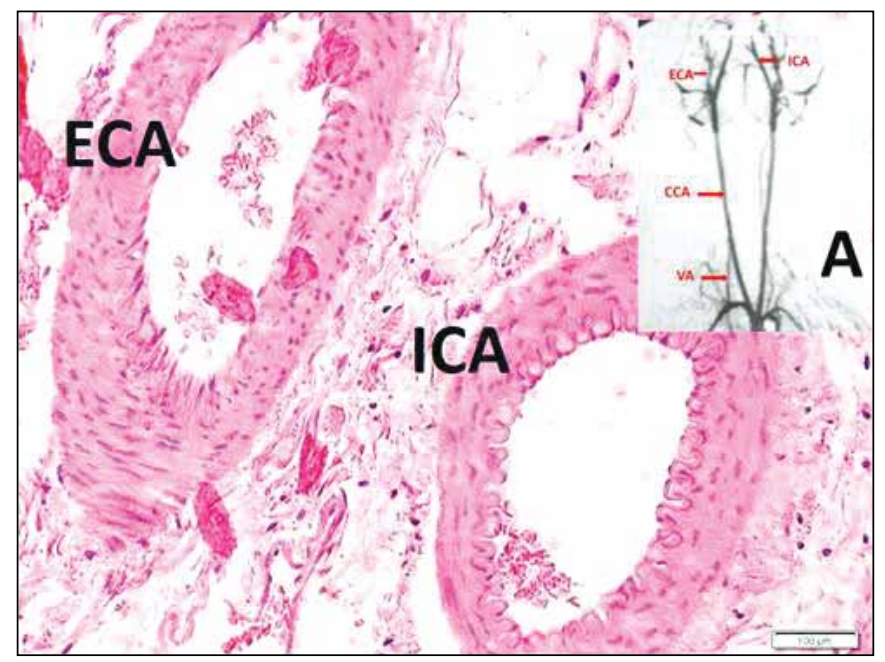

Figure 1: Normal carotid angiogram of a rabbit (A/Archives of corresponding author) and histological appearances of external carotid artery (ECA) and internal carotid arteries (ICA) are seen (H\&E, x4).

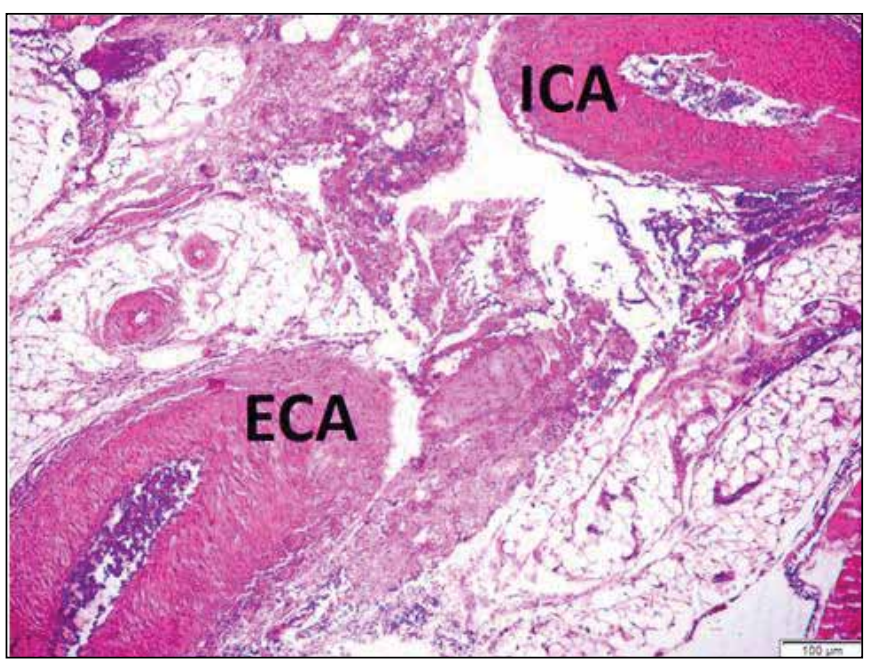

Figure 3: Histopathological appearances of external carotid artery (ECA) and internal carotid arteries (ICA) are seen (H\&E, x4) in a rabbit with a slight degree of ECA vasospasm following $\mathrm{SAH}$. tological appearance of a normal temporal cortex, and histopathological appearance of temporal cortex with normal and apoptotic neurons with severe ECA vasospasm.

The cervical carotid artery and its branches were measured in 23 consecutive rabbits. The mean $\pm S D$ size of the common carotid artery was $1.95 \pm 0.25 \mathrm{~mm}$, the main trunk of the ECA $1.10 \pm 0.26 \mathrm{~mm}$, and the ICA was $1.01 \pm 0.19 \mathrm{~mm}$. Normal temporal cortex glial cells density was estimated as $136.950 \pm 9.257 / \mathrm{mm}^{3}$ in normal rabbits, $131.324 \pm 7.987 / \mathrm{mm}^{3}$ in sham, $112.320 \pm 6.112 / \mathrm{mm}^{3}$ in slight ECA vasospasm and $97.543 \pm 5.432 / \mathrm{mm}^{3}$ in severe ECA vasospasm. The mean VSI values of ECA were estimated as $1.95 \pm 0.21 ; 2.15 \pm 0.29$; $2.95 \pm 0.65$ and $3.12 \pm 0.276$, respectively (Table I). Statistical differences between the VSI values of ECA and degenerated

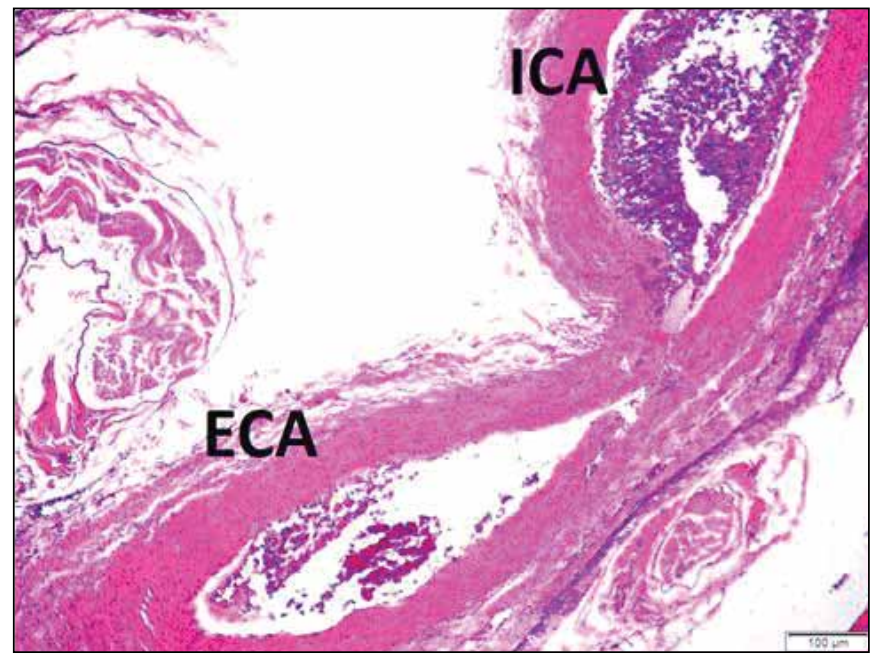

Figure 2: Histopathological appearances of external carotid artery (ECA) and internal carotid arteries (ICA) are seen (H\&E, x4) in a rabbit with no more vasospasm developed sample following $\mathrm{SAH}$.

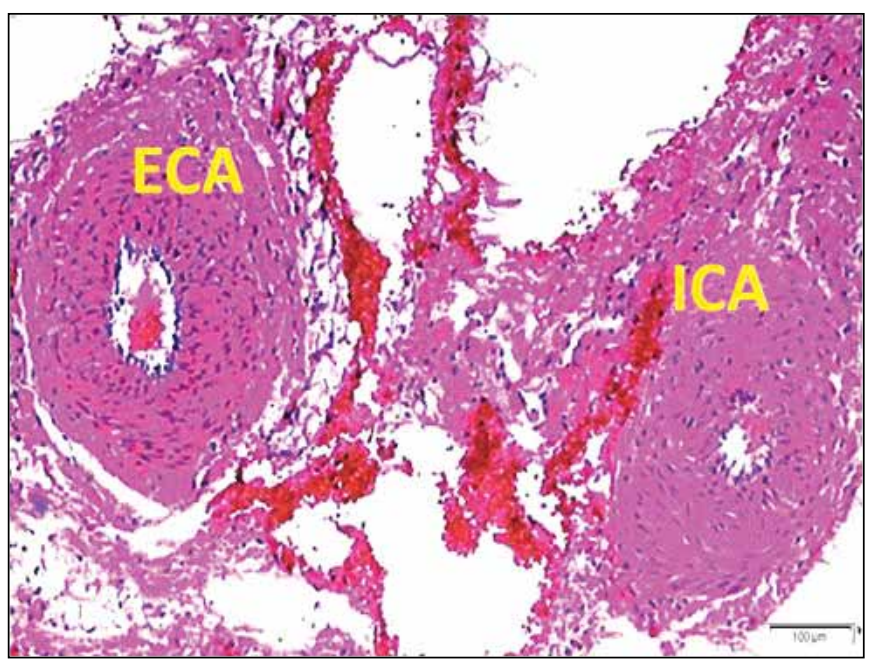

Figure 4: Histopathological appearances of external carotid artery (ECA) and internal carotid arteries (ICA) are seen (H\&E, x4) in a rabbit with severe ECA and ICA vasospasm following SAH. 


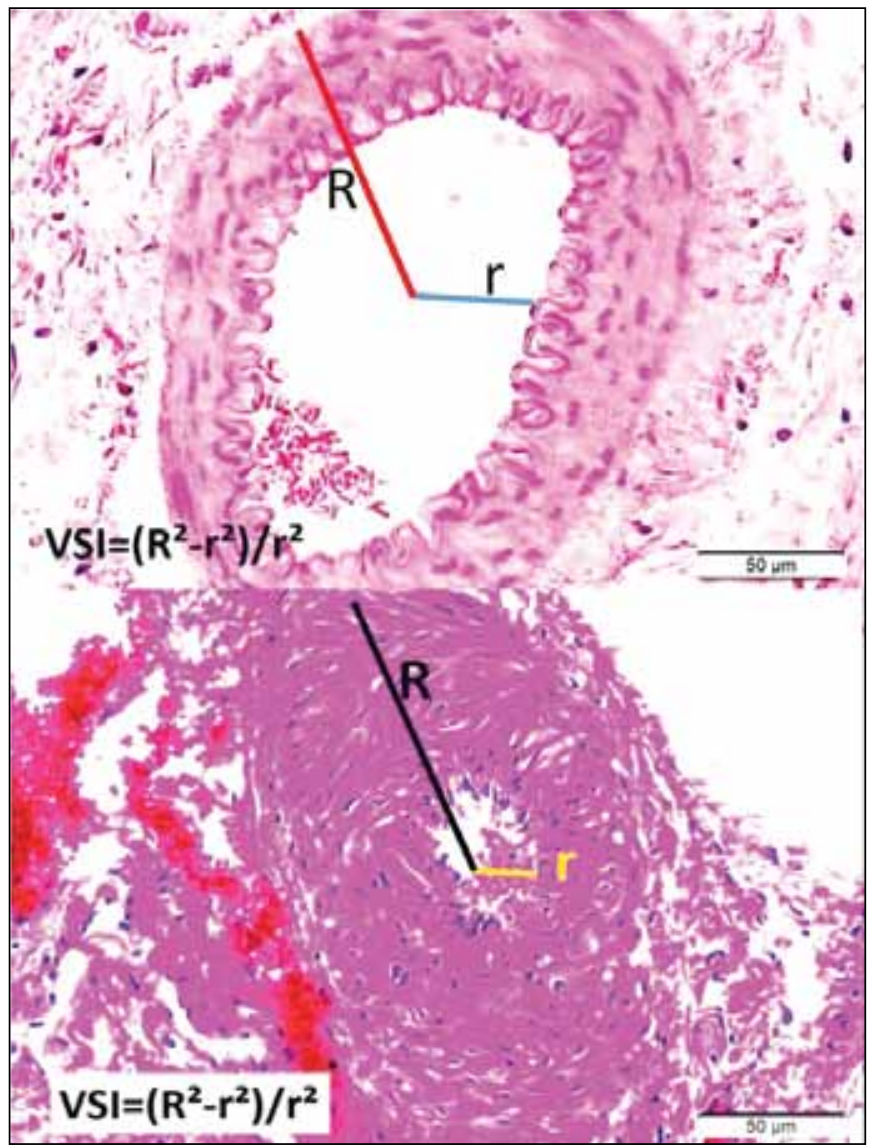

Figure 5: VSI value estimation methods are seen in external carotid arteries (ECA) (H\&E, x4) both normal and severe vasospasm developed animals following $\mathrm{SAH}$. neuron densities in temporal cortices were significant ( $p$ $<0.005)$. The difference was more significant for the severe vasospasm group $(\mathrm{p}<0.0001)$.

\section{DISCUSSION}

Cerebral vasospasm is a frequent complication after $\mathrm{SAH}$ contributing to overall morbidity and mortality. Various neuronal, humoral, and chemical factors are involved in cerebral vessel innervation $(12,14,23)$.

Nitric oxide (NO) is a vasodilatory substance. However, NO may have a detrimental effect on the vascular system by reactive induction of inducible nitric oxide synthase (iNOS) in $\mathrm{SAH}$ (67). The peroxidation of membrane proteins by the nitric oxide metabolite may contribute to the morphological damage in chronic vasospasm (50). Calcitonin gene related peptide (CGRP) is a neurotransmitter with tachykinins in sensory fibers in the cerebral vasculature with possible vasodilating properties. The trigeminal cerebrovascular system may be involved in SAH (33). Neuropeptide Y-like immunoreactivity (NPY-L1) levels were increased compared to controls in patients with hemodynamic changes. CGRP - L1 levels were also increased in connection with vasospasm (32-34).

Parasympathetic fibers have vasodilation effect, and sympathetic fibers have vasoconstrictor effect on cerebral arteries (69). Dysfunction of neuronal signal processing and transmission occurs after SAH and contributes to the high morbidity and mortality. The underlying mechanism may be neuronal cell death. Direct influence of subarachnoid blood metabolites on neuronal signaling should also be considered (69).

Autonomic nerve fibers provide neural innervation. The postganglionic fibers of the ciliary ganglion of the third cranial

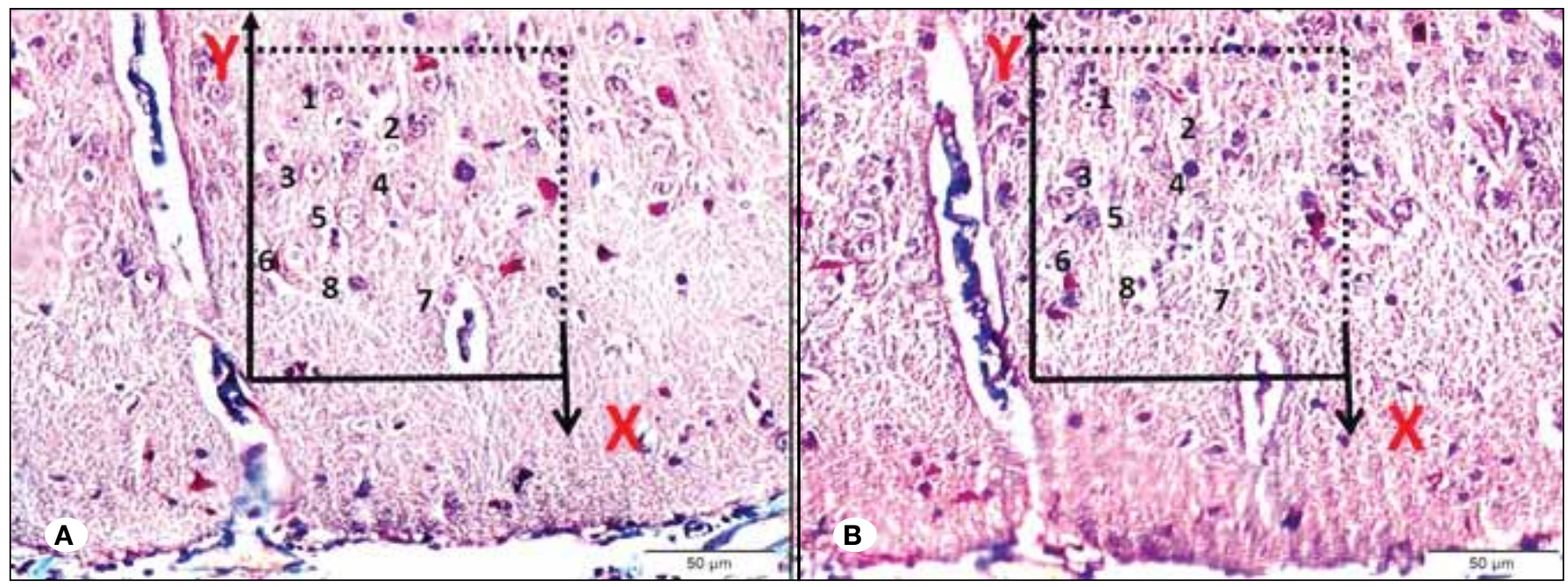

Figure 6 A, B: Stereologic cell counting of the superior temporal lobe in a rabbit. A, B were taken from two parallel, adjacent thin sections separated by a distance of $5 \mu \mathrm{m}$. The upper and right lines represent the inclusion lines, and the lower and left lines are exclusion lines. The number of neurons from the two dissectors occurs in a volume given by the product of the counting frame area and the distance

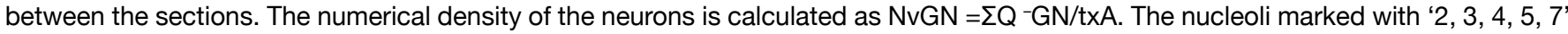
are dissector particles in A. Section B shows them as they disappeared. The nucleoli marked with '2, 3, 7, 8' are not a dissector particle in A. Section B shows '1, 6, 8' as it disappeared (TUNEL, x10). 
Table I: Vasospasm Index (VSI) of External Carotid Artery (ECA) in Control, Sham, Slight and Severe ECA Vasospasm Group; and Temporal Cortex Glial Cell Number in These Groups Respectively $(p<0.005)$

\begin{tabular}{lcccc}
\hline Parameter & Control & Sham & \multicolumn{2}{c}{ ECA Vasospasm } \\
\hline VSI of ECA & & \multicolumn{2}{c}{ Slight } & Severe \\
\hline Temporal cortex glial cells $\left(/ \mathrm{mm}^{3}\right)$ & $136.950 \pm 9.257 / \mathrm{mm}^{3}$ & $131.324 \pm 7.987 / \mathrm{mm}^{3}$ & $112.320 \pm 6.112 / \mathrm{mm}^{3}$ & $97.543 \pm 5.432 / \mathrm{mm}^{3}$ \\
\hline
\end{tabular}

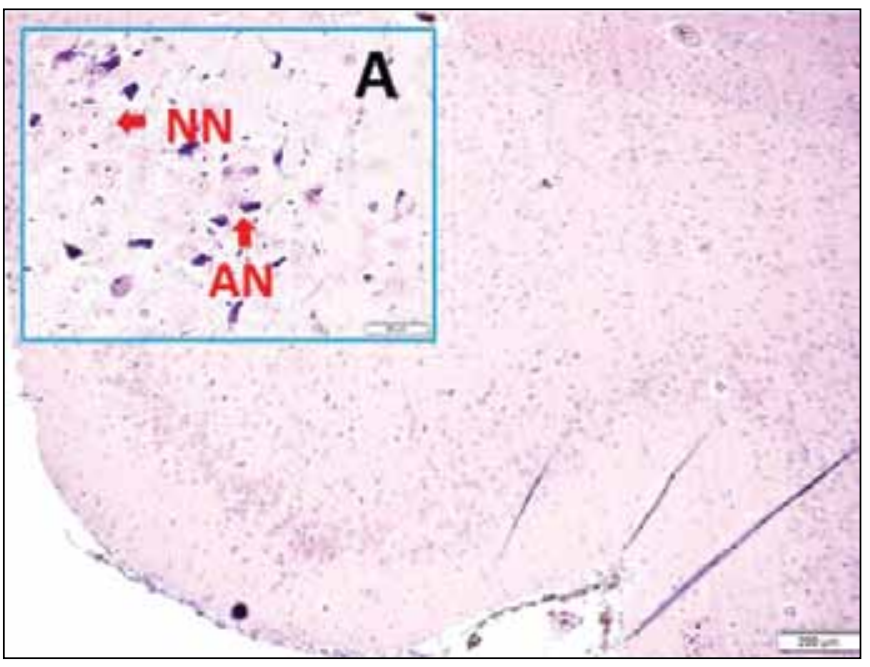

Figure 7: Histological appearance of a normal temporal cortex (LM, Tunnel, x4/Base), and histopathological appearance of temporal cortex with normal and apoptotic neurons with severe ECA vasospasm (LM, Tunnel, x10).

nerve, the ganglion of the fifth cranial nerve, the sphenopalatine ganglion of the seventh cranial nerve, the otic ganglion of the ninth cranial nerve are involved in the parasympathetic effect. The sympathetic innervations by the postganglionic fibers of the superior sympathetic ganglion contribute to the carotid plexus and cause vasospasm of the cerebral vessels (69).

The intra-and extracerebral vessels are innervated by trigeminal fibers. Large cerebral arteries are primarily innervated by the ophthalmic branch of the trigeminal nerve and cause vasodilation (69). Cerebrovascular sensory nerves mainly originating from the first division of the ipsilateral trigeminal ganglion are known as the trigemino-cerebrovascular system (63). The trigeminal ganglion neuron density was reported to be an important factor in the regulation of anterior choroidal artery (AChA) diameter and cerebral blood flow. Low neuron density of ophthalmic root of the trigeminal ganglion might play a role in the pathogenesis of AChA vasospasm after SAH (69).

Decreased neuron density in the petrosal ganglion is associated with high blood pressure (3). The vagus nerves serve as an essential link in the neurogenic vasodilatation of the intracranial arteries. Bilateral dilatation of the cerebral arteries by the stimulation of the vagus nerve was reported to be possible only in case of the preservation of the greater petrosal nerve (56).

Cerebral vasospasm causes neuronal and astrocytic apoptosis after SAH. SAH causes ischemic insults to the vagal nerve ganglia and ischemic neurodegeneration in the petrosal ganglia resulting in hypertension by decreasing the number of neurons in these ganglia (52).

The cerebral vasculature, in particular the pial vessels, are densely supplied with noradrenergic sympathetic nerve fibers mainly originating in the superior cervical ganglion, accompanying the carotid artery, and projecting into the ipsilateral hemisphere. Ischemic injury of the upper cervical ganglions after $\mathrm{SAH}$ may cause vasospasm of the anterior spinal arteries (63).

Intracerebral hemorrhage causes descending neurodegeneration from the cortex to the dorsal root ganglion (DRG) (55). The low neuron density of the $\mathrm{C} 3$ dorsal root ganglia was reported to be related with severe vasospasm of anterior spinal artery (35). Retrograde neuronal death is well established in dorsal root ganglia after peripheral nerve injury or spinal cord trauma $(4,5)$. Upper cervical ganglions innervate anterior spinal arteries (ASA). Ischemic injuries after SAH may cause vasospasm at the ASA as a result of vasospasm of the arteries supplying $D R G$, leading to ischemic degeneration in the DRG. SAH results in neurodegeneration in DRG and C4 dorsal root ganglia (63). Low neuron density of the C4 dorsal root ganglia may be considered as an important factor in the pathogenesis of severe respiratory disturbances in $\mathrm{SAH}$ (63). Parasympathetic ischemia of the lower cranial nerve ganglions and DRG may have the major effect on the vasospasm of the external carotid artery. Spinal SAH should also be considered in the development of ECA vasospasm since the ASA vasospasm is related with the DRG ischemia (35).

High neuron density of the stellate ganglion can be considered as sympathetic overactivity that causes basilar vasospasm and neovascularisation, whereas low neuron density of stellate ganglion can be considered as sympathetic hypoactivity that prevents basilar vasospasm and causes vascular wall thinning after bilateral common carotid artery ligation (39).

In fatal $\mathrm{SAH}$, respiratory muscles are paralyzed due to ischemia of vagal nerve and other upper and lower cervical nerve injuries. The parasympathetic system plays a major role in the continuation of spontaneous respiration. In $\mathrm{SAH}$, vagal nerve roots are affected by vasospasm $(6,7,10,15)$. 
A brief review of the literature discloses the importance of the neurohumoral mechanisms and autonomic nervous system on vasospasm after SAH but vasospasm of the extracranial arteries are rarely reported and discussed.

Clinically recurrent strokes due to transient vasospastic occlusions of the ICA have been observed whereas recurrent vasospasms of the extracranial ICA are rare. ECA vasospasm after SAH has been reported even less commonly. Migrainous vasospasms of the extracranial ICA have been asserted to be associated with sympathetic vasomotor innervation and adrenoreceptor blockade was proposed as a treatment option $(31,68)$. In the angiography of a patient with posterior inferior cerebellar artery (PICA) aneurysm, fibromuscular dysplasia was observed in the external carotid and vertebral arteries (27).

After the rupture of an intracranial aneurysm, vasospasm of the extracranial as well as intracranial arteries was reported. Digital subtraction angiography revealed severe vasospasm of the external carotid arteries (46). Superior cervical ganglionectomy and perivascular sympathectomy of cervical ICA improved the symptoms. In 23 angiographically investigated patients, ECA vasospasm was observed in $50 \%$. Pathogenesis of the vasospasm of the external carotid arteries was reported to be related with the sympathetic nerves (24).

Collateral system plays an important role in case of occlusion of the arteries. In cerebral vasospasm, this system is expected to be on stage. The suboccipital network consists of anastomoses of the cervical, vertebral, occipital, and carotid arteries. This arterial network has a salvaging effect in arterial occlusions. The suboccipital knot enlarges to provide collateral blood flow from subclavian to external carotid artery giving extravascular support to the brain by way of intraorbital ophthalmic anastomoses $(2,8)$. These important anastomotic vascular channels between the extracranial and intracranial arteries are located in three regions along the skull base: the orbital region via the ophthalmic artery between the internal maxillary artery (IMA) and ICA; the petrocavernous region via the inferolateral trunk, the petrous branches of the internal carotid artery, the meningohypophyseal trunk to the carotid artery; and the upper cervical region via the ascending pharyngeal, the occipital, and the ascending and deep cervical arteries to the vertebral artery $(17,28,44)$.

In SAH patients, cerebral catheter angiography showed segmental vasoconstriction involving bilateral internal carotid, posterior cerebral and external carotid branches. External carotid artery branch involvement in reversible cerebral vasoconstriction syndrome was reported (58). Trapping of the ICA in the acute stage of the subarachnoid hemorrhage may result in ischemia secondary to hemodynamic hypoperfusion or occlusion of the perforating artery with delayed vasospasm. Evaluation of the ECA-ICA bypass is important (43).

Since the temporal lobe receives blood from both the carotid and the vertebrobasilar systems (41), vasospasm of both internal and external carotid arteries increases the morbidity impairing the collateral salvation system. Temporal lobe degeneration leads to psychiatric pathologies $(20,37)$. Bilateral damage to the medial temporal lobe has been reported to cause severe and lasting impairment in declarative memory. The affected structures are hippocampal region with the CA fields, the dentate gyrus, and the subicular complex and the adjacent perirhinal, entorhinal, and parahippocampal gyrus (45). Studies have shown psychiatric co-morbidities in temporal lobe epilepsy and temporal lobe atrophy in relation to Alzheimer's disease $(13,22,36,51,66)$.

In our study, ECA vasospasm together with ICA vasospasm has led to temporal lobe degeneration due to lack of collateral supply. Diagnosis and treatment of vasospasm is important at the early stage before the development of cerebral ischemia.

Our study has also shown that ECA vasospasm together with the intracerebral vasospasm have more deleterious effect on the brain, leading to neurodegeneration. We hypothesize that the ischemic degeneration of the lower cranial nerve ganglions and DRG have a major influence on the external vasospasm of the arteries. The sympathetic overdischarge during this phase with the depression of the parasympathetic activity should be also taken into consideration.

Medical treatment is the initial step when clinical vasospasm is suspected. Papaverine, Amrinone, Milrinone, Verapamil, Nimodipine, Nicardipine and Fasudil hydrochloride are pharmacological agents used in the treatment. Intrathecal nicardipine has been reported to be effective for the prevention and treatment of vasospasm (21). Memantine can prevent SAH by restoring endothelial nitric oxide synthase (29).

The vagal system has been proposed to modulate the inflammatory system through acetycholine receptors. The neuroinflammatory reflex is vagally mediated that may relate to parasympathetic nervous system activation that suppresses inflammation.

Parasympathetic dysfunction coupled with catecholamine release may play a role in unchecked inflammation leading to myocardial dysfunction and cell death (49) and in the inflammatory cascade leading to vasospasm after SAH $(16,49)$.

At the early stage of SAH parasympathetic activity is enhanced (65). The acute activation was supposed to contribute to cardiac injury. Subcutaneous vagal nerve blockage at the beginning of $\mathrm{SAH}$, whereas vagal nerve stimulation or sympathetic nerve blocks was proposed as a treatment method $(1,49)$.

ICA is innervated mainly by the superior cervical sympathetic nerve and the stimulation of this nerve results in cerebral vasoconstriction. Several reports have proposed cervical sympathectomy as a successful treatment method. Blood flow increase is observed especially in spastic vessels (24).

ECA may be spared during the acute stage of $\mathrm{SAH}$, before the ischemia of the lower cranial parasympathetic and dorsal root ganglia with an early intervention.

Early endovascular treatment of cerebral vasospasm by mechanical dilatation with balloon angioplasty and pharmacological dilatation with intraarterial drug infusion or combination therapy is the treatment of choice (21). 
Flow augmentation strategies are used as a novel and alternative therapeutic option for $\mathrm{SAH}$-induced cerebral vasospasm (42). A dual balloon catheter designed to increase cerebral blood flow (CBF) via partial occlusion of the aorta above and below the origin of the renal arteries, intraaortic balloon pump counter pulsation in patients refractory to triple- $\mathrm{H}$ therapy are reported as new methods of treatment (21).

Transcutaneous electrical nerve stimulation (TENS) and spinal cord stimulation have been shown to influence peripheral and CBF through a sympathetic pathway $(61,62,64)$.

Sphenopalatine ganglion stimulation activates perivascular vasodilatory nerves in the ipsilateral anterior circle of Willis. Sphenopalatine ganglion stimulation was reported to decrease vasospasm and increase CBF after SAH in monkeys and it was associated with opening of the blood-brain barrier (59).

Cervical sympathetic block can relieve cerebral vasospasm after SAH and increase NO content and NOS activity in plasma and cerebrospinal fluid to promote neural functional recovery (19).

The neuron number of stellate ganglia may play an important role in the regulation of basilar artery volume. Stellate ganglia ablation may prevent severe vasospasm after SAH (39).

Stimulation of the ophthalmic branch of the trigeminal ganglion may be a therapeutic option in the prevention of severe vasospasm in SAH (54).

Radial artery graft bypass with ICA sacrifice was considered as a treatment method in the acute phase of SAH (40). ECA-radial artery-M2 segment of the MCA bypass was used for the treatment of large or giant ICA aneurysms (30). Revascularization technique with direct and indirect bypass surgery has been used for the treatment of ischemic neurological symptoms (38).

Extracranial-intracranial bypass is performed in patients with atherosclerotic MCA occlusion, ischemic symptoms or poor cerebral hemodynamics unresponsive to medical treatment $(18,30)$. The ischemic area surrounding the cerebral infarction in the eloquent area was reported to be saved by superficial temporal artery (STA)-MCA bypass surgery (60).

STA-MCA minimally invasive bypass procedures were performed for anastomosis recently (26). STA-MCA anastomosis is a direct bypass considered to be effective for the acute improvement of cerebral hemodynamics (70). The rapid increase of the CBF due to direct bypass in the acute stage of cerebral infarction was thought to cause cerebral edema, hemorrhage, and reperfusion injuries. However, these complications were not observed in the recently reported studies (70).

Vasospasm of venous grafts in extra-intracranial bypass was observed, though the patients were treated successfully with calcium antagonists as well as hypertensive and hypervolemic medication (57).

STA-MCA and STA-ACA double anastomosis with pansynangiosis was reported to have excellent outcome. Double by- pass with indirect bypass or single bypass in the treatment of acute stage of ischemia may prevent the neurological deterioration (71).

ECA stenting with STA-MCA anastomosis is regarded as a good therapeutic option with symptomatic ICA occlusion and severe stenosis of the ipsilateral ECA (53).

External carotid spasm together with intracranial spasm has a more severe neurodegenerative effect than cerebral vasospasm alone. Medical and invasive methods have been proposed in the treatment of vasospasm after $\mathrm{SAH}$. The important point is to intervene as early as possible in the acute stage of $\mathrm{SAH}$, when the parasympathetic activity is dominant and yet collaterals are not impaired.

The non-invasive, functional neurosurgical treatment methods increasing the parasympathetic activity or endovascular and bypass techniques may be life-saving in the early period before the ischemia develops and infarct settles.

\section{CONCLUSION}

ECA vasospasm is an important predictive factor on the serious cerebral ischemia and neuronal degeneration after $\mathrm{SAH}$ that has not been extensively mentioned in the literature. We theorized that decreased vasodilatatory functions of cervical dorsal root ganglia, trigeminal-glossopharyngealvagal nerves and/or increased vasospastic effects of cervical sympathetic ganglia may be responsible for this phenomenon.

\section{REFERENCES}

1. Araz O, Aydin MD, Gundogdu B, Altas E, Cakir M, Calikoglu C, Atalay C, Gundogdu C: Preventive role of hilar parasympathetic ganglia on pulmonary artery vasospasm in subarachnoid hemorrhage: An experimental study. Turk Neurosurg 25: 519525, 2015

2. Ayad $M$, Viñuela F, Rubinstein $E H$ : The suboccipital carrefour: Cervical and vertebral arterial anastomosis. AJNR Am J Neuroradiol 19: 925-931, 1998

3. Aydin MD, Bayram E, Atalay C, Aydin N, Erdogan AR, Gundogdu C, Diyarbakirli S: The role of neuron numbers of the petrosal ganglion in the determination of blood pressure: An experimental study. Minim Invasive Neurosurg 49: 359-361, 2006

4. Aydin MD, Dane S, Gundogdu C, Gursan: Neurodegenerative effects of monopolar electrocauterization on spinal ganglia in lumbar disc surgery. Acta Neurochir (Wien) 146:1125-1129, 2004

5. Aydin MD, Erdogan AR, Cevli SC, Gundogdu C, Dane S, Diyarbakirli S: Ganglionary mechanisms of spasticity and ileus in cerebral hemorrhage: an experimental study. Int J Dev Neurosci 24: 455-459, 2006

6. Aydin MD, Eroglu A, Turkyilmaz A, Erdem AF, Alici HA, Aydin N, Altas S, Unal B: The contribution of chemoreceptor-network injury to the development of respiratory arrest following subarachnoid hemorrhage. Eurasian J Med 42: 47-52, 2010 
7. Aydin MD, Kanat A, Yilmaz A, Cakir M, Emet M, Cakir Z, Aslan S, Altas S, Gundogdu C: The role of ischemic neurodegeneration of the nodose ganglia on cardiac arrest after subarachnoid hemorrhage: An experimental study. Exp Neurol 230: 90-95, 2010

8. Aydin MD, Ozkan U, Gundoğdu C, Onder A: Protective effect of posterior cerebral circulation on carotid body ischemia. Acta Neurochir (Wien) 144(4):369-372, 2002

9. Aydin MD, Serarslan Y, Gundogdu C, Aydin N, Aygul R, Kotan $D$, Ulvi $H$, Onder A, Kanat A: The relationship between the neuron density of the trigeminal ganglion and the posterior communicating artery vasospasm in subrachnoid hemorrhage: An experimental study. Neurosurg Q 22: 1-6, 2012

10. Aydin MD, Ungoren MK, Izci Y, Acikel M, Gundogdu C, Gursan $\mathrm{N}$ : Vagal nerve degeneration and pulmonary artery vasospasm after subarachnoid hemorrhage. Journal of Neurological Sciences (Turkish) 30: 369-376, 2013

11. Aygul R, Aydin MD, Kotan D, Demir R, Ulvi H, Karalar M, Nalbantoglu NG, Eseoglu M: Role of the trigeminal system on posterior communicating artery remodelization after bilateral common carotid artery ligation. Anal Quant Cytopathol Histpathol 35: 217-225, 2013

12. Bederson JB, Germano IM, Guarino L: Cortical blood flow and cerebral perfusion pressure in a new noncraniotomy model of subarachnoid hemorrhage in the rat. Stroke 26: 1086-1091, 1995

13. Bonner MF, Price AR: Where is the anterior temporal lobe and what does it do? J Neurosci 33: 4213-4215, 2013

14. Brawley BW, Strandness DE Jr, Kelly WA: The biphasic response of cerebral vasospasm in experimental subarachnoid hemorrhage. J Neurosurg 28(1): 1-8, 1968

15. Cakir M, Atalay C, Cakir Z, Emet M, Aydin MD, Aydin N, Onder A, Calik M: The role of vagal nerve root injury on respiration disturbances in subarachnoid hemorrhage. Turk Neurosurg 25: 273-278, 2015

16. Carr KR, Zuckerman SL, Mocco J: Inflammation, cerebral vasospasm, and evolving theories of delayed cerebral ischemia. Neurol Res Int 2013:506584, 2013

17. Chong CT, Chin KJ, Yip LW, Singh K: Case series: Monocular visual loss associated with subarachnoid hemorrhage secondary to ruptured intracranial aneurysms. Can J Anaesth 53: 684-689, 2006

18. Chou CW, Chang JH, Lin SZ, Cho DY, Cheng YW, Chen CC. Extracranial-intracranial (EC-IC) bypass of symptomatic middle cerebral artery (MCA) total occlusion for haemodynamic impairment patients. Br J Neurosurg 26: 823-826, 2012

19. Chun-Jing H, Shan O, Guo-Dong L, Hao-Xiong N, Yi-Ran L, Ya-Ping F: Effect of cervical sympathetic block on cerebral vasospasm after subarachnoid hemorrhage in rabbits. Acta Cir Bras 28: 89-93, 2013

20. Cotter D, Mackay D, Frangou S, Hudson L, Landau S: Cell density and cortical thickness in Heschl's gyrus in schizophrenia, major depression and bipolar disorder. $\mathrm{Br} \mathrm{J}$ Psychiatry 185:258-259, 2004

21. Dabus G, Nogueira RG: Current options for the management of aneurysmal subarachnoid hemorrhage-induced cerebral vasospasm: A comprehensive review of the literature. Interv Neurol 2: 30-51, 2013
22. de Oliveira GN, Kummer A, Salgado JV, Portela EJ, SousaPereira SR, David AS, Teixeira AL: Psychiatric disorders in temporal lobe epilepsy: An overview from a tertiary service in Brazil. Seizure 19: 479-484, 2010

23. Edvinsson L, Uddman R, Juul R: Peptidergic innervation of the cerebral circulation. Role in subarachnoid hemorrhage in man. Neurosurg Rev 13: 265-272, 1990

24. Endo S, Hori S, Suzuki J: Vasoconstriction of external carotid arteries after rupture of intracranial aneurysms. Acta Neurochir (Wien) 50: 281-287, 1970

25. Eseoglu M, Yilmaz I, Karalar M, Aydin MD, Kayaci S, Gundogdu C, Gunaldi O, Onen MR: The role of sympathectomy on the regulation of basilar artery volume changes in stenoocclusive carotid artery modeling after bilateral common carotid artery ligation: An animal model. Acta Neurochir (Wien) 156:963-969, 2014

26. Fischer G, Senger S, Sharif S, Oertel J: Superficial temporal artery to middle cerebral artery bypass via a minimized approach: Operative nuances and problem solving aspects. World Neurosurg 88:97-103, 2016

27. Fuse T, Umezu M, Yamamoto M, Demura K, Nishikawa $Y$, Niwa Y: External carotid artery aneurysm developing after embolization of a ruptured posterior inferior cerebellar artery aneurysm in a patient with cervicocephalic fibromuscular dysplasia-case report. Neurol Med Chir (Tokyo) 46: 290-293, 2006

28. Geibprasert S, Pongpech S, Armstrong D, Krings T: Dangerous extracranial-intracranial anastomoses and supply to the cranial nerves: Vessels the neurointerventionalist needs to know. AJNR Am J Neuroradiol 30: 1459-1468, 2009

29. Huang CY, Wang LC, Shan YS, Pan CH, Tsai KJ: Memantine attenuates delayed vasospasm after experimental subarachnoid hemorrhage via modulating endothelial nitric oxide synthase. Int J Mol Sci16: 14171-14180, 2015

30. Ishishita Y, Tanikawa R, Noda K, Kubota H, Izumi N, Katsuno M, Ota N, Miyazaki T, Hashimoto M, Kimura T, Morita A: Universal extracranial-intracranial graft bypass for large or giant internal carotid aneurysms: Techniques and results in 38 consecutive patients. World Neurosurg 82: 130-139, 2014

31. Janzarik WG, Ringleb PA, Reinhard M, Rauer S: Recurrent extracranial carotid artery vasospasms: report of 2 cases. Stroke 37: 2170-2173, 2006

32. Juul R, Edvinsson L, Fredriksen TA, Ekman R, Brubakk AO, Gisvold SE: Changes in the levels of neuropeptide $\mathrm{Y}$-LI in the external jugular vein in connection with vasoconstriction following subarachnoid haemorrhage in man. Involvement of sympathetic neuropeptide $\mathrm{Y}$ in cerebral vasospasm. Acta Neurochir (Wien) 107: 75-81, 1990

33. Juul R, Edvinsson L, Gisvold SE, Ekman R, Brubakk AO, Fredriksen TA: Calcitonin gene-related peptide-LI in subarachnoid haemorrhage in man. Signs of activation of the trigemino-cerebrovascular system? Br J Neurosurg 4: 171-179, 1990

34. Juul R, Hara H, Gisvold SE, Brubakk AO, Fredriksen TA, Waldemar G, Schmidt JF, Ekman R, Edvinsson L: Alterations in perivascular dilatory neuropeptides (CGRP, SP, VIP) in the external jugular vein and in the cerebrospinal fluid following subarachnoid haemorrhage in man. Acta Neurochir (Wien) 132: 32-41, 1995 
35. Kanat A, Yilmaz A, Aydin MD, Musluman M, Altas S, Gursan $\mathrm{N}$ : Role of degenerated neuron density of dorsal root ganglion on anterior spinal artery vasospasm in subarachnoid hemorrhage: Experimental study. Acta Neurochir (Wien) 152: 2167-2172, 2010

36. Kandratavicius L, Lopes-Aguiar C, Bueno-Júnior LS, RomcyPereira RN, Hallak JE, Leite JP: Psychiatric comorbidities in temporal lobe epilepsy: Possible relationships between psychotic disorders and involvement of limbic circuits. Rev Bras Psiquiatr 34: 454-466, 2012

37. Kates WR, Miller AM, Abdulsabur N, Antshel KM, Conchelos J, Fremont W, Roizen N: Temporal lobe anatomy and psychiatric symptoms in velocardiofacial syndrome (22q11.2 deletion syndrome). J Am Acad Child Adolesc Psychiatry 45: 587-595, 2006

38. Kawashima M, Rhoton AL Jr, Tanriover N, Ulm AJ, Yasuda A, Fujii K: Microsurgical anatomy of cerebral revascularization. Part I: Anterior circulation. J Neurosurg 102:116-131, 2005

39. Kayaci S, Kanat A, Aydin MD, Musluman AM, Eseoglu M, Karalar M, Gundogdu C: Role of neuron density of the stellate ganglion on regulation of the basilar artery volume in subarachnoid hemorrhage: An experimental study. Auton Neurosci 165: 163-167, 2011

40. Kazumata K, Nakayama N, Nakamura T, Kamiyama $H$, Terasaka S, Houkin K: Changing treatment strategy from clipping to radial artery graft bypass and parent artery sacrifice in patients with ruptured blister-like internal carotid artery aneurysms. Neurosurgery 10 Suppl 1: 66-72, 2014

41. Kiernan JA: Anatomy of the temporal lobe. Epilepsy Res Treat 2012:176157, 2012

42. Knappertz VA, Tegeler CH, Myers LG: Clinical cerebrovascular applications of arterial ultrasound volume flow rate estimates. J Neuroimaging 6: 1-7, 1996

43. Kubo Y, Koji T, Yoshida K, Saito H, Ogawa A, Ogasawara $\mathrm{K}$ : High-flow bypass and wrap-clipping for ruptured blood blister-like aneurysm of the internal carotid artery using intraoperative monitoring of cerebral hemodynamics. Vasc Health Risk Manag 11: 297-302, 2015

44. Lee JS, Hamilton MG, Zabramski JM: Variations in the anatomy of the rabbit cervical carotid artery. Stroke 25: 501503, 1994

45. Levy DA, Bayley PJ, Squire LR: The anatomy of semantic knowledge: Medial vs. lateral temporal lobe. Proc Natl Acad Sci U S A 101: 6710-6715, 2004

46. Longo M, Blandino A, Ascenti G, Ricciardi GK, Granata F, Vinci S: Cerebral angiography in the rat with mammographic equipment: A simple, cost-effective method for assessing vasospasm in experimental subarachnoid haemorrhage. Neuroradiology 44: 689-694, 2002

47. Macdonald RL, Pluta RM, Zhang JH: Cerebral vasospasm after subarachnoid hemorrhage: the emerging revolution. Nat Clin Pract Neurol 3: 256-263, 2007

48. Marder CP, Narla V, Fink JR, Tozer Fink KR: Subarachnoid hemorrhage: Beyond aneurysms. AJR Am J Roentgenol 202: 25-37, 2014

49. Mashaly HA, Provencio JJ: Inflammation as a link between brain injury and heart damage: The model of subarachnoid hemorrhage. Cleve Clin J Med Suppl 2:S26-30, 2008
50. Medele RJ, Stummer W, Reulen HJ, Steiger HJ: Evidence for peroxidative damage by nitric oxide in experimental chronic cerebral vasospasm. Neurol Res 18: 277-280, 1996

51. Miller MI, Younes L, Ratnanather JT, Brown T, Trinh H, Postell E, Lee DS, Wang MC, Mori S, O'Brien R, Albert M; BIOCARD Research Team: The diffeomorphometry of temporal lobe structures in preclinical Alzheimer's disease. Neuroimage Clin 3: 352-360, 2013

52. Musluman AM, Aydin MD, Yilmaz A, Cansever T, Kanat A, Gundogdu C, Cakir Z, Emet M, Gursan N, Aydin N, Unal B: The effect of degenerated neuron density of petrosal ganglion on the development of blood pressure variabilities after subarachnoid hemorrhage in a rabbit model: An experimental study. Turk Neurosurg 21: 559-566, 2011

53. Oku T, Nogami K, Koizumi $H$, Ishihara $H$, Kato $S$, Fujisawa $H$, Suzuki M: External carotid artery stenting and superficial temporal artery to middle cerebral artery anastomosis for internal carotid artery occlusion with external carotid artery severe stenosis: Case report. Neurol Med Chir (Tokyo) 52: 906-909, 2012

54. Onder A, Serarslan Y, Aydin MD, Aydin N, Ulvi H, Kotan D, Aygul R, Gundogdu: The role trigeminal ganglion neuron density in the prevention of subarachnoid hemorrhage induced basilar artery vasospasm: An experimental study. Neurosurg Q 19: 264-269, 2009

55. Ozturk C, Kanat A, Aydin MD, Yolas C, Kabalar ME, Gundogdu B, Duman A, Kanat IF, Gundogdu C: The impact of L5 dorsal root ganglion degeneration and Adamkiewicz artery vasospasm on descending colon dilatation following spinal subarachnoid hemorrhage: An experimental study; first report. J Craniovertebr Junction Spine 6: 69-75, 2015

56. Ryba M, Głowicki K, Zalewski W, Januszewski S, Kukwa A: Influence of vagal input on cerebral blood flow in monkeys and dogs after experimental cerebral vasospasm. Acta Neurobiol Exp (Wars) 45: 163-171, 1985

57. Santoro A, Piccirilli M, Ciappetta P, Guidetti G, Cantore G: Vasospasm of venous grafts in extra-intracranial by-pass. Report of two cases. J Neurosurg Sci 49: 107-115, 2005

58. Shaik S, Chhetri SK, Roberts G, Wuppalapati S, Emsley HC: Reversible cerebral vasoconstriction syndrome with involvement of external carotid artery branches. Neurohospitalist 4: 141-143, 2014

59. Takahashi M, Zhang ZD, Macdonald RL: Sphenopalatine ganglion stimulation for vasospasm after experimental subarachnoid hemorrhage. J Neurosurg 114: 1104-1109, 2011

60. Tamano Y, Usuda Y, Ujiie H, Izawa M, Ishii K, Takakura K: Usefulness of positron emission tomography to STA-MCA anastomosis for the case with cerebral infarction. No Shinkei Geka 26: 532-538, 1998

61. ter Laan M, van Dijk JM, Staal JM, Elting JJ: Electrical modulation of the sympathetic nervous system in order to augment cerebral blood flow: A protocol for an experimental study. BMJ Open 1:e000120, 2011

62. ter Laan M, van Dijk JM, Stewart R, Staal MJ, Elting JW: Modulation of cerebral blood flow with transcutaneous electrical neurostimulation (TENS) in patients with cerebral vasospasm after subarachnoid hemorrhage. Neuromodulation 17: 431-436; discussion 436-437, 2014 
63. Ulvi H, Demir R, Aygul R, Kotan D, Calik M, Aydin MD: Effects of ischemic phrenic nerve root ganglion injury on respiratory disturbances in subarachnoid hemorrhage: An experimental study. Arch Med Sci 9: 1125-1131, 2013

64. Visocchi M, Argiolas L, Meglio M, Cioni B, Basso PD, Rollo M, Cabezas D: Spinal cord stimulation and early experimental cerebral spasm: The "functional monitoring" and the "preventing effect". Acta Neurochir (Wien) 143:177-185, 2001

65. Visocchi M, Di Rocco F, Ciampini A, Di Muro L: A new animal model for monitoring the early cerebral vasospasm after subarachnoid haemorrhage. J Neurosurg Sci 50: 89-94, 2006

66. Wegiel J, Flory M, Kuchna I, Nowicki K, Ma SY, Imaki H, Wegiel J, Cohen IL, London E, Wisniewski T, Brown WT: Stereological study of the neuronal number and volume of 38 brain subdivisions of subjects diagnosed with autism reveals significant alterations restricted to the striatum, amygdala and cerebellum. Acta Neuropathol Commun 2: 141, 2014
67. Widenka DC, Medele RJ, Stummer W, Bise K, Steiger HJ: Inducible nitric oxide synthase: A possible key factor in the pathogenesis of chronic vasospasm after experimental subarachnoid hemorrhage. J Neurosurg 90: 1098-1104, 1999

68. Wöpking S, Kastrup A, Lentschig M, Brunner F: Recurrent strokes due to transient vasospasms of the extracranial internal carotid artery. Case Rep Neurol 5: 143-148, 2013

69. Yilmaz A, Gundogdu C, Aydin MD, Musluman M, Kanat A, Aydin Y: Trigeminal ganglion neuron density and regulation of anterior choroid artery vasospasm: In a rabbit model of subarachnoid hemorrhage. Surg Neurol Int 2: 77, 2011

70. Yokosawa M, Hayashi T, Shirane R, Tominaga T: Efficacy of superficial temporal artery-middle cerebral artery double anastomoses in a patient with rapidly progressive moyamoya disease: Case report. Neurol Med Chir (Tokyo) 54:836-840, 2014

71. Yu-Tse L, Ho-Fai W, Cheng-Chi L, Chu-Mei K, Yi-Chou W, Tao-Chieh Y: Rupture of symptomatic blood blister-like aneurysm of the internal carotid artery: Clinical experience and management outcome. Br J Neurosurg 26: 378-382, 2012 